\title{
INDIGENOUS COMMUNITIES FROM OAXACA, MEXICO. HEALTH PROBLEMS, OPPORTUNITIES AND CHALLENGES IN PUBLIC HEALTH WITH SPECIAL ATTENTION IN MENTAL HEALTH
}

\author{
COMUNIDADES INDÍGENAS DE OAXACA, MÉXICO. PROBLEMAS, OPORTUNIDADES Y RETOS EN SALUD \\ PÚBLICA CON ATENCIÓN ESPECIAL EN SALUD MENTAL
}

Helda Pinzón-Pérez', Leoncio Vásquez Santos²

\begin{abstract}
Oaxacans come from the Mexican state of Oaxaca and have relocated primarily in the Central Valley of California, Los Angeles, and San Diego. They are the fastest growing farm-worker population in California and are estimated to be between 100,000 and 150,0001 . This community is affected by various health problems, which have been exacerbated by the COVID-19 pandemic. This article intends to familiarize the reader with the cultural characteristics of the Indigenous Mexican Oaxacan communities and their health care needs, especially in mental health, the main programs and services carried out, the challenges of nurses and public health workers in this situation, and present an instrument in Mixtec, Zapotec, and Spanish to assess the mental health of this population. Also, to provide recommendations on how this instrument could be useful for the mental health of these indigenous communities and from other Latin American regions.
\end{abstract}

Key words: Oaxaca; Indigenous Health; Mental Health; Health Promotion; Indigenous Communities (source: MeSH NLM).

\section{RESUMEN}

Los Oaxaqueños provienen del estado Mexicano de Oaxaca y se han trasladado principalmente al Valle Central de California, Los Ángeles y San Diego. Son la población de trabajadores agrícolas de más rápido crecimiento en California y se estiman entre 100000 y 150000 1. Esta comunidad se ve afectada por diversos problemas de salud, que se han visto agravados por la pandemia de COVID-19. Este artículo pretende familiarizar al lector con las características culturales de las comunidades indígenas Oaxaqueñas y sus necesidades de atención en salud, especialmente en salud mental, así como con los principales programas y servicios que se llevan a cabo, los desafíos de los profesionales de enfermería y trabajadores de salud pública en esta situación, y presentar un instrumento en mixteco, zapoteco y español para evaluar la salud mental de esta población. Asimismo, brindar recomendaciones sobre cómo este instrumento podría ser útil para la salud mental de estas comunidades indígenas y de otras regiones Latinoamericanas.

Palabras clave: Oaxaca; Salud Indígena; Salud Mental; Promoción de la Salud; Comunidades Indígenas ú (fuente: DeCS BIREME). 


\section{INTRODUCTION}

Oaxacans, as presented by Kresge ${ }^{(1)}$, come from the Mexican state of Oaxaca and have relocated primarily in the Central Valley of California, Los Angeles, and San Diego. They are the fastest growing farm-worker population in California and are estimated to be between 100,000 and 150,000 . This community is affected by marginalization, poverty, lack of health insurance, substandard housing, and increased levels of stress and anxiety ${ }^{(19)}$.

These conditions are a challenge for public health, which requires a particularly multicultural and responsible approach, counting on the participation of the population in solving health problems. This article intends to familiarize the reader with the cultural characteristics of the Indigenous Mexican Oaxacan communities and their health care needs, especially in mental health, the main programs and services carried out, the challenges of nurses and public health workers in this situation, and an instrument to measure the mental health of this population.

\section{INDIGENOUS COMMUNITIES FROM OAXACA}

Pinzon-Perez ${ }^{(2)}$ acknowledged in a previous publication that the term indigenous is a controversial term because it has been associated with historical maltreatment, as well as cultural oppression and inequity. Recent denominations considered to be more respectful and embracive of cultural appropriateness include aboriginal, native, and first nation groups. The term indigenous will be used in this manuscript since many of the original literature sources consulted for this article use such terminology. In addition, the term native will also be used to acknowledge the cultural relevance and heritage of the Oaxacan groups.

Oaxacans are people from the State of Oaxaca, Mexico, which is home to 17 different indigenous groups ${ }^{(3)}$. The word Oaxaca is a derivation of the Nahuatl word, Huaxyacac, which means "The Place of the Seed" because of a tree commonly found in the region ${ }^{(4)}$. Indigenous Oaxacans have historically engaged in farming activities, which were their main occupation in Mexico. The indigenous Oaxacan communities migrated to the United States from 1942 to 1965, predominately via the agricultural recruitment program called the Bracero Program and in the 1970s and 1980s through other agricultural recruitment initiatives ${ }^{(1)}$.

The indigenous communities from Oaxaca are closeknit groups known as "transnational communities"(5). Indigenous Oaxacan communities are exceptional as each group is geographically different, with its own unique history, economic challenges, and barriers6. In the United States, California is home to one of the fastest-growing indigenous Oaxacan communities ${ }^{(7,}$ 8). According to the 2000 U.S. Census, there were more than 150,000 indigenous Oaxacans living in California, where the largest concentration of Oaxacans is located in the Central Valley9, primarily due to farming activities. California is nationally known as the agricultural production leader in the U.S., where the Central Valley is home to the most diverse agricultural commodities. The Central Valley farming industry relies on foreign migrant workers such as the indigenous Oaxacan communities. Therefore, these workers are crucial in supplying food to drive the economy, and they usually undertake the most physically demanding and laborious work. With regard to languages, in Southern Mexico, OtoManguean Native American languages are spoken largely in the Oaxacan region. The two most spoken of these languages are Mixtec and Zapotec, spoken by approximately 1.5 million people in this region. The Zapotec language is the most used language in the region of Oaxaca ${ }^{(4)}$.

The Zapotecan group is divided into Zapotecans and Chatinos, primarily denoting the areas in which they live. They speak Zapotec and Chatino languages. The Popolopan group includes the Mazatecs, the Chochos, the Ixcatecs, and the Popolucans. They speak Ha shuta Enima, Nahuatl, and Ixcatec. The Amuzgo-Mixtecan group speak Mixtec, Amuzgo, Cuicatec, Triqui, and Tacuate. Other languages spoken in the region of Oaxaca include Mixe, Zoque, Huave, and Chontal ${ }^{(1,4)}$.

The California Institute for Rural Studies estimated that in the Central Valley, the Oaxacan communities' most spoken dialects are Mixtec, Triqui, Zapotec, Chanitno, and Amusco ${ }^{(1)}$. The Binational Center for the Development of Indigenous Oaxacan Communities listed additional languages such as Tlapaneco and Nahuatl as being spoken in the Central Valley of California ${ }^{(3)}$

\section{PROGRAMS AND SERVICES}

In California, the National Indigenous Institute, Office of the Governor of Oaxaca, and the National 
Program of Solidarity with Farm Workers have been advocating for the indigenous Oaxacan communities throughout the state. However, this is not the case in all U.S. states. In the Central California Valley, the Binational Center for the Development of Oaxacan Indigenous Communities, created in 1993, is one of the leading non-for-profit organizations providing services for migrant Oaxacans living in California. Such services include educational events, advocacy for workers' rights, orientation, counseling and advising, as well as referrals based upon specific identified needs ${ }^{(3)}$.

According to this organization, each community has unique cultural traits and language that make them different from each other, but they face similar problems as migrants and their experience of migration appears to be universal. Programs offered by this Center include the cultural sensitivity trainings, Access to Health Care and Prevention Program ${ }^{(3)}$, among others discussed below.

Exemplary initiatives of advocacy and transformation of the Determinants of Health for indigenous communities are the programs offered by the Binational Center for the Development of Oaxacan Indigenous Communities. One of those programs is "The Indigenous Interpreters Program" which is a collaboration of the Indigenous Front of Binational Organizations (FIOB for the corresponding Spanish acronym), The Binational Center for the Development of Oaxacan Indigenous Communities (CBDIO for the corresponding Spanish acronym) and California Rural Legal Assistance (CRLA). This program attempts to reduce educational, judicial, and social inequities by providing interpreting services in indigenous languages such as Mixtec, Zapotec, Triqui, Chatino, and Tlapaneco(3).

Another exemplary program is the "Xi'na Navali (The Children First)" in which the CBDIO strengthens social safety nets for Oaxacan indigenous migrant families with children from 0 to 5 years of age. In this program, participating families receive assistance on how to navigate and use the health care and educational systems of California ${ }^{(3)}$.

A third exemplary program is "Building Healthy Communities (BHC) Leve le tu Latiezh mas guen (Zapoteco Alto)." In this program participants are empowered to advocate for themselves and receive training on how to conduct meetings with governmental officials as well as with members of their communities. Participants attend legislative visits and public forums and take active part in policy development. Additional exemplary programs conducted by CBDIO include the "Immigration program" in which participants receive assistance with completing the paperwork and procedures for U.S. citizenship and renewal of their Deferred Action applications, as well as the program "Guelaguetza California" which is a cultural celebration of the feast of Lunes del Cerro with displays of traditional clothing and foods ${ }^{(3)}$.

The U.S. has one of the best health care systems in the world and is in a unique position to support disadvantaged communities. It is essential that health care systems develop programs that reflect the complexity of disenfranchised groups and be prepared to support the health needs of these communities. Currently, there is a significant lack of culturally sensitive programs and limited native language materials that promote an understanding of the indigenous Oaxacan communities in the United States and around the world. Looking at existing global health promotion programs for indigenous Oaxacan communities may give Nurse Practitioners and Public Health Workers insights for future initiatives to strengthen and improving the health of Oaxacan communities.

\section{HEALTH PROBLEMS}

Currently, Indigenous Oaxacan communities face the threat of COVID-19 as everyone else in the world. Statistics continue to change as the COVID-19 pandemic is being controlled through vaccinations and public health measures. As of December 17, 2020, a total of 26,645 cases of COVID-19 and 2,034 deaths were reported in the region of Oaxaca, Mexico. A total of 11,799 new cases and 718 deaths occurred as of December 17, 2020. This is in comparison to the statistics provided for Mexico in general, which reveal a total of 1.29 million cases and 116,000 deaths ${ }^{(10)}$.

In the United States as of December 17, 2020 a total of 17.4 million cases and 313,000 COVID-19 deaths were reported. California reported 1.7 million cases and 22,221 deaths ${ }^{(10)}$. In the Fresno County of the Central California Valley, as of December 18, 2020 a total number 49,918 cases and 557 deaths were documented $^{(11)}$. The Central California Valley includes the following 19 counties: Butte, Colusa, Glenn, Fresno, Kern, Kings, Madera, Merced, Placer, San Joaquin, Sacramento, Shasta, Solano, Stanislaus, Sutter, Tehama, Tulare, Yolo, and Yuba ${ }^{(12)}$. 
As of March 12, 2021, an estimated 2.6\% of the global population $(202,508.023$ people) have received at least one dose of the available COVID-19 vaccines and $0.96 \%(75,139,404$ persons) have been fully vaccinated. In the United States, $19.52 \%(645,071,674$ persons) have received at least one dose and $10.32 \%$ $(33,863,127$ persons) have been fully vaccinated. In Mexico, $2.26 \%$ of the population ( $2,882,000$ persons) have received at least one dose and $0.48 \%(606,000$ persons) have been fully vaccinated 10 . Specific vaccination rates for Oaxacans living in the US and in Mexico were unavailable at the time this manuscript was written.

On the other hand, malnutrition, intestinal parasitism, iron-deficiency anemia, higher infant mortality rates, higher maternity mortality rates, as well as higher rates of tuberculosis and other infectious diseases are commonly found in native/indigenous groups in the American continent ${ }^{(13)}$. In addition, illnesses labeled by Montenegro and Stephens as "diseases of acculturation" such as diabetes, hypertension, and obesity emerge as important threats to the health of native communities in the American continent and around the globe. These diseases are considered modern conditions generated by changing nutritional behaviors to fit modern standards of living13. Research in Oaxacan populations is needed on the rates of these emerging diseases and other health issues that often accompany them.

Despite the growth of the Oaxacan community in the U.S., there has not been enough research unveiling the specific health needs and barriers faced by this population group. The existing health disparities among the indigenous Oaxacan communities demand more health intervention programs to closely address the health risks of this community. For instance, it is anecdotally known that mental health is one of the major health concerns among the Mixtec and Zapotec communities in the Central California Valley, yet limited research is currently being conducted on this pressing issue.

Indigenous Oaxacans have higher poverty rates, lack of health insurance, higher rates of teenage pregnancy, alcohol abuse, and domestic violence as well as increased levels of mental stress, anxiety, and depression ${ }^{(1)}$. Limited data is available on the incidence and prevalence rates of mental health conditions and psychiatric illnesses in this population. Of special importance is the design of culturally relevant mental health materials and information available in their native languages. As stated by Kresge, "limited Spanish skills and lack of written indigenouslanguages are some of the most significant barriers to outreach among this population. Other factors limiting access to health and social services include fears associated with immigration status, limited professional interpretation services and limited access to transportation, particularly in more rural and isolated communities"(1).

\section{MENTAL HEALTH CALLENGES}

Indigenous Oaxacan communities have distinct cultural practices and multiple language barriers, which make them vulnerable to poor outcomes and health disparities. Studies show that indigenous Oaxacan's cultural practices include the use of traditional medicine ${ }^{(14)}$. Recommendations for mental health care in this population group include the involvement of traditional healers as valuable resources in mental health assessment and treatment for indigenous/native communities. In addition, an interesting model to address the mental health needs of communities is the involvement of community health workers in evidence-based community mental health programs. Barnett et al. conducted a systematic review of 43 articles corresponding to 39 research trials conducted in the United States and in low- and middle-income countries. The results of this review yielded results that show significant symptom reduction and modification of mental health disparities ${ }^{(15)}$.

Rhett-Mariscal proposed the creation of Promotores in Mental Health programs to strengthen the Prevention and Early Intervention (PEI) elements of the Mental Health Services Act (MHSA). Rhett-Mariscal indicated that promotores are essential in reducing health disparities associated with transportation, culture, linguistic barriers, as well as access to mental health services due to location, mistrust, fear, and stigma ${ }^{(16)}$. The Promotores in Mental Health program could be an effective model for Latinx communities, specifically Oaxacans, in the U.S. and abroad.

A study on the genetic counseling needs of Indigenous People of Oaxaca in the Central Valley of California ${ }^{(17)}$ reinforced the value of community involvement. This study reported on two Oaxacan families, "one extended family with an early lethal inborn error of metabolism and the other with a chronic disfiguring form of ichthyosis"(17). This study emphasized the importance of recognizing the 
various language dialects, adapting our healthrelated interventions to cultural interaction patterns, valuing traditional medicine practices, and designing transmission of understandable genetic terms and concepts.

\section{NEED FOR AN INSTRUMENT TO MEASURE MENTAL HEALTH}

The need for a mental health instrument for Oaxacans was evidenced by the calls for culturallysensitive health programs requested by community organizations and reinforced in the document "Indigenous Diaspora:Today, we celebrate. Tomorrow we continue to organize" in which Miguel Villegas, Coordinator of the Binational Center for Oaxacan Indigenous Communities COVID-19 Equity Project in Fresno, California stated that "Our communities fear COVID-19 testing because of public charge. We need to change that immediately because it saves lives"(18).

A research instrument to assess mental health problems among Oaxacan indigenous communities was created in the summer of 2020 by a Spanishspeaking advanced practice nurse, Dr. PinzonPerez, who is a family nurse practitioner (FNP) with a doctorate (Ph.D.) in Health Education, and the other two team members, a university public health student and a nurse practitioner from Oaxaca. They work in Fresno, which is a rural area of California, where there are a large number of Oaxacans, who speak 16 different languages ${ }^{(19)}$. They translated into the most common languages spoken by Oaxacan indigenous communities in the Central Valley of California: Spanish, Mixteco and Zapotec.

The team created a written version in Spanish and an oral/audio version in English for Mixtec and Zapotec since according to the participating Registered Nurse and Public Health worker, these last two languages are oral languages and do not have a written form. The ultimate goal of this mental health instrument was to reduce health disparities in congruence with the public health functions of Assessment, Policy Development and Assurance, as well as with the following ten Essential Public Health Services:"1. Assess and monitor population health. 2. Investigate, diagnose and address health hazards and root causes. 3. Communicate effectively to inform and educate. 4. Strengthen, support and mobilize communities and partnerships. 5. Create, champion and implement policies, plans and laws. 6. Utilize legal and regulatory actions. 7. Enable equitable access. 8. Build a diverse and skilled workforce.9. Improve and innovate through evaluation, research and quality improvement. 10. Build and maintain a strong organizational infrastructure for public health"(20).

The mental health instrument introduced in this manuscript intended to be an example of culturally and health-literacy appropriate tools for Oaxacan Indigenous communities. It included questions on the perception of COVID-19 risk, its implications on their mental health, and other relevant mental health constructs. It was created based upon literacy levels and cultural aspects relevant to this indigenous group. This article does not intend to present the validation of the instrument or other research methodological considerations, but rather to present a narrative on how it can be used as a tool for the mental health of indigenous communities from Oaxaca, Mexico.

The instrument included 23 mental-health related questions, from which four were directly related to COVID-19. The Registered Nurse translated the instrument into Zapotec, the Public Health worker translated it into Mixtec and the Nurse Practitioner translated the instrument into Spanish. The proposed mental health instrument is now available in three languages: Spanish, Mixtec, and Zapotec.

The ultimate and most important goal of these activities was to serve the Oaxacan community via this mental health instrument and to strengthen the collaborations between the involved university, the Oaxacan community, and local organizations serving this group. The involvement of Community Mental Health Workers, through models such as Promotores de Salud Mental (PSMs) or Mental Health Community Advocates (MHCAs), in the planning, implementation, and evaluation of the mental health instrument discussed in this manuscript could be a crucial component of this initiative. The inclusion of PSMs and MHCAs will result in more effective and culturally appropriate interventions for early detection of mental health concerns, timely referrals, and prompt treatment.

The proposed mental health instrument is available for use by anyone around the world who could benefit from it, including Oaxacan communities, advocacy organizations, nurse practitioners, and public health workers, among others. For a copy of the mental health instrument, please contact the corresponding author of this manuscript. 


\section{CHALLENGES AND OPPORTUNITIES FOR NURSES PRACTITIONERS AND PUBLIC HEALTH WORKERS}

The American Association of Nurse Practitioners (AANP) defines FNPs as advanced practice registered nurses (APRNs) who provide health care services for all ages. According to the AANP, "FNPs maintain patient records; perform physical examinations; order or perform diagnostic tests; prescribe medications; develop treatment plans; and treat acute and chronic illnesses, conditions, and injuries that fall under primary care ${ }^{\prime \prime(21)}$.

To become a Nurse Practitioner (NP), the provider "must hold a bachelor's degree in nursing, be licensed as a registered nurse (RN), graduate from a nationally accredited graduate NP program that meets national standards for advanced didactic and clinical education and pass a national NP board certification exam." ${ }^{\prime \prime 21)}$. These strict training and practice guidelines have been the basis for Nurse Practitioners' Full practice authority in some states of the United States of America. According to AANP "In Full Practice Authority (FPA) states, NP licensure is not contingent on unnecessary contracts or relationships with a physician or oversight by the state medical board" ${ }^{\prime 211)}$.

Nurse Practitioners tend to work in rural and underserved areas with "the highest care quality and safety standards"(21). They are trained with an approach to holist care, which includes an emphasis on mental health.

On the other hand, according to the American Public Health Association (APHA) "Public health promotes and protects the health of people and the communities where they live, learn, work and play... While a doctor treats people who are sick, those of us working in public health try to prevent people from getting sick or injured in the first place $^{\prime \prime(22)}$. Public Health practitioners include a vast gamma of workers such as health educators, community health workers, and public health professionals. They prevent the installment of disease via primary, secondary, and tertiary prevention and promote wellness and healthy lifestyles. Public Health workers track disease outbreaks, conduct scientific research, educate communities, teach individuals about healthy behaviors, and promote the creation of conditions that maximize health ${ }^{(22)}$.

Opportunities for Nurse Practitioners and Public
Health workers could be based on the approaches proposed by Rufino Dominguez. Dominguez advocated for educating Oaxacan communities on their rights, motivating women to become new sources of leadership, building a solid foundation to promote social action via policy changes and community cohesion, and restoring the value of the Oaxacan history and culture through social events such as concerts, as well as sports and cultural events to motivate young Oaxacans to feel proud of their heritage ${ }^{(19)}$.

Since FNPs and public health practitioners work in clinics, communities, health care settings, private practice, and other health care systems, they have a major role in health education, health promotion, and disease prevention. Their capacity to meet the needs of the communities they serve, such as the Oaxacans, could be enhanced by pursuing additional certifications such as diabetes, pain management, obesity control, and geriatric care, among other ${ }^{21}$.

One challenge is the resistance to change in health care systems. Nurse practitioners and Public Health Workers are agents of change via advocacy and transformation of the Determinants of Health. As indicated by the American Public Health Association, public health workers"... shed light on why some of us are more likely to suffer from poor health than others. The many facets of public health include speaking out for laws that promote [health]..., spreading the word about ways to stay healthy and giving science-based solutions to problems"(22).

According to the American Public Health Association, "Everyone should have a fair and just opportunity to achieve good health and well-being... To achieve optimal health for all, the Essential Public Health Services actively promote policies, systems and services that enable good health and seek to remove obstacles and systemic and structural barriers such as poverty, racism, gender discrimination, and other forms of oppression - that have resulted in health inequalities ${ }^{\prime \prime 20)}$. Nurse Practitioners and Public Health Workers should actively work to reduce health inequalities in mental health.

\section{CONCLUSION}

The health problems faced by the indigenous communities of Oaxaca, Mexico, continue to be an important challenge for public health, requiring special attention and the use of correctly culturally validated instruments, especially in mental health. 
Financial Support: This project was supported by a grant from the California State University College of Health \& Human Services Chancellor's Office 20/21 RSCA award and by a grant from the Provost Research and Creative Activities award 21/22 from the California State University College of Health \& Human Services.

Author's contributions: Dr. Helda Pinzon-Perez: Conducted the bibliographic review, writing the first draft of the article - wrote the first draft of the article, incorporated co-author suggestions, obtained financing, and drafting and approval of the final version of the article. Mr. Leoncio Vásquez Santos: Provided cultural advice for the writing of this article, participated in the design and translation of the mental health instrument mentioned in this article, participated in the bibliographic review, reviewed the first draft of the article and provided suggestions for its improvement, and approval of the final version of the article.

Conflict of Interest: The authors declare no conflict of interest in the publication of this article.

Acknowledgements: Special gratitude to Mrs. Herlinda Jimenez-Daugherty and Mr. Leoncio Vasquez for the translation of the mental health instrument into Mixtec and Zapotec. Additional gratitude is owed to Ms. Chia Thao for her help in some components of the literature review for this article.

Received: May 26, 2021

Approved: July 09, 2021

\section{BIBLIOGRAPHIC REFERENCES}

1. Kresge, L. Indigenous Oaxacan Communities in California: An Overview. California Institute for Rural Studies. 2007 [cited May 24, 2021]. Available at: https://cirsinc.org/ and www.safsf.org/wpcontent/uploads/.../2015_Aug26_IndigenousHealthWeb_Report.p

2. Pinzon-Perez, H. Health Needs of Native/Indigenous Communities in the San Joaquin Valley of the United States: Implications for Public Health Practitioners in Peru and Other Parts of the Americas. 2017. [cited May 24, 2021]. Available at ev. Fac. Med. Hum. 2017;17(2):64-70. DOI 10.25176/RFMH.v17.n2.835

3. Binational Center for the Development of Oaxacan Indigenous Communities. About CBDIO. Fresno Programs. 2020. [cited May 24 2021]. Available at: https://www.centrobinacional.org/ and https:// www.centrobinacional.org/fresno

4. Schmal, J. Oaxaca: Land of Diversity. 2007. [cited May 24, 2021]. Available at: http://www.latinola.com/story.php?story $=3908$

5. Kearney, M., Nagengast, C.. Anthropological perspectives on transnational communities in rural California. No. 3. California Institute for Rural Studies, 1989. [cited May 24, 2021]. Available at: Kearney \& Nagengast, 1989, transnational communities - Google Scholar

6. Cohen, J. H. The Culture of Migration in Southern Mexico. 2004. [cited May 24, 2021]. Available at: Introduction_to_Culture_of_Migration. pdf (d1 wqtxts1xzle7.cloudfront.net)

7. Aguirre International. The California Farm Labor Force: Overview and Trends from the National Agricultural Workers Survey. Aguirre International, 2005. [cited May 24, 2021]. Available at: aguirre international 2005 agricultural workers - Google Scholar

8. Kresge, L. Indigenous Oaxacan Communities in California: An Overview. California Institute for Rural Studies. 2007. [cited May 24, 2021]. Available at: Indigenous Oaxacans in CA_FINAL_6-07-08.PDF (ncfh.org) and https://cirsinc.org/

9. U.S. Census Brief (2000). Overview of Race and Hispanic Origin. [cited May 24, 2021]. Available at: Overview of Race and Hispanic Origin: 2000 (census.gov)

10. John Hopkins University. CSSE COVID-19 Data. 2020. [cited December 18, 2020 and March 12, 2021.] Available at https://github.com/ CSSEGISandData/COVID-19

11. Fresno County Health Department. COVID-19 (Novel Coronavirus) 2020. [cited May 24, 2021]. Available at: https://www.co.fresno.ca.us/ departments/public-health/COVID-19

12. American Museum of Natural History. Grace California Central Valley. 2017. [cited May 24, 2021]. Available at: https://www.amnh.org/ learn-teach/curriculum-collections/grace/grace-tracking-water-fromspace/california-central-valley
13. Montenegro R., Stephens C. Indigenous Health in Latin America and the Caribbean. Lancet 2006; 367: 1859-69

14. González-Vázquez, T., Pelcastre-Villafuerte,B., and Taboada, A. "Surviving the distance: the transnational utilization of traditional medicine among Oaxacan migrants in the US." Journal of immigrant and minority health 18, no. 5 (2016): 1190-1198. [cited May 24, 2021]. Available at: Surviving the Distance-The Transnational Utilization.pdf

15. Barnett, M. Gonzalez, A., Miranda, J., Chavira, and D., Lau, A. Mobilizing Community Health Workers to Address Mental Health Disparities for Underserved Populations: A Systematic Review. 2018. [cited May 24, 2021]. Available at: https://www.ncbi.nlm.nih.gov/pmc/articles/ PMC5803443/

16. Rhett-Mariscal, W. Promotores in Mental Health in California and the Prevention and Early Intervention Component of the MHSA. Policy Paper for The California Endowment and prepared by the Center for Multicultural Development at the California Institute for Mental Health. 2008. [cited May 24, 2021]. Available at: https://losangeles. networkofcare.org/library/Promotores1.pdf

17. Shen, J. Carmichael, J. and Vásquez Santos, L. Identifying and Addressing Genetic Counseling Challenges among Indigenous People of Oaxaca-One Center's Experience with Two Immigrant Farmworker Families in the Central Valley of California. Journal of Genetic Counseling, 27:996-1004. 2018. [cited May 24, 2021]. Available at https://doi.org/10.1007/s10897-018-0221-0

18. Binational Center for the Development of Oaxacan Indigenous Communities. Indigenous Diaspora: Today, we celebrate. Tomorrow we continue to organize. 2020. [cited May 24, 2021]. Available at: https://www.centrobinacional.org/post/indigenous-diaspora-todaywe-celebrate-tomorrow-we-continue-to-organize

19. Dominguez, R. Cultural Roots as a Source of Strength: Educating and Organizing a Fragmented Immigrant Community. 2003. [cited May 24, 2021]. Available at: https://wagner.nyu.edu/files/leadership/16.pdf

20. American Public Health Association. 10 Essential Public Health Services. 2020. [cited May 24, 2021]. Available at: https://www.apha. org/what-is-public-health/10-essential-public-health-services

21. American Association of Nurse Practitioners. 2020. [cited May 24 2021]. Available at: https://www.aanp.org/news-feed/are-youconsidering-a-career-as-a-family-nurse-practitioner

22. American Public Health Association. What is Public Health. 2020. [cited May 24, 2021]. Available at: https://www.apha.org/what-is-publichealth 